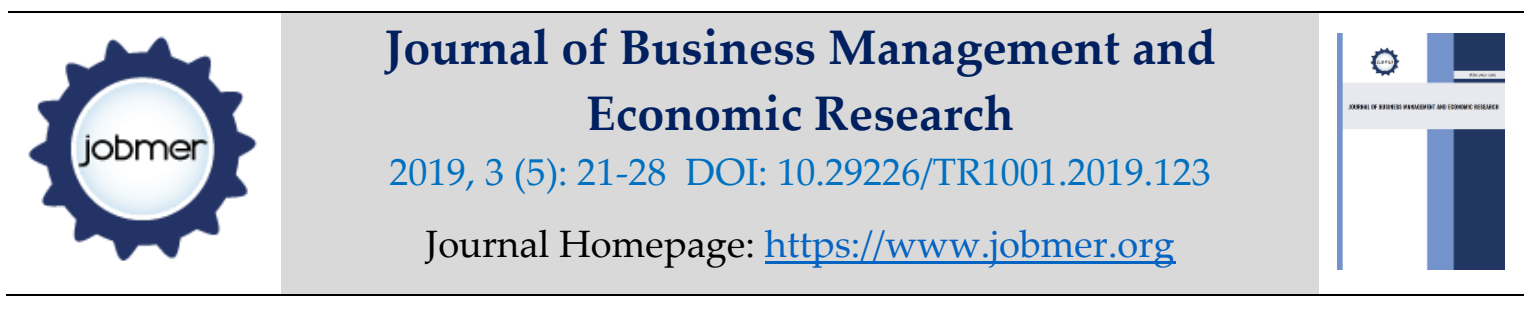

\title{
Identifying the Factors Affecting the Competitiveness of Rice Industry in Vietnam
}

\author{
Phan Thi Thanh Tam \\ Thai Nguyen University of Technology \\ thanhtamdhktcn87@gmail.com
}

\begin{abstract}
s
This research was conducted to identify the factors affecting the competitiveness of rice industry in Viet Nam. Research findings show that there are five groups of factors affecting the competitiveness of rice industry, including: the conditions of production factor group; household characteristics; State support; Market signals; and support of enterprises and traders. Based on the analysis results, the author has proposed some recommendations to improve the competitiveness of the rice industry in Vietnam.
\end{abstract}

Keywords: Competitiveness, rice, Vietnam

\section{Introduction}

In recent years, agricultural production in our country has achieved remarkable achievement which including the rice industry. Vietnam's rice always has high rankings in the world. Currently, Vietnamese rice has been exported to 135 countries and territories around the world; and for the first time Vietnam surpassed Thailand to become the top rice exporter in the world. However, the rice industry is still facing many challenges and competition in both domestic and international markets. In addition, when the level of integration of Vietnam becomes more and more extensive, bilateral and multilateral agreements signed and implemented will open up great opportunities for Vietnam's rice industry to penetrate into difficult markets like the US, Japan, EU ...But it also face many challenges such as: concerns about quality, food safety and the 
level of product positioning in the markets of countries, technical barriers in the developed countries.

Improving capacity of rice industry competitiveness is an urgent requirement in the current period when competitive market is increasingly fierce. If not improving competitiveness, the rice industry is at risk of failure at domestic market. To improve the rice industry's competitiveness, the identifying of the factors affecting and quantifying the impact of those factors on the competitiveness of the rice industry is issues should be top priority. At the same time, this study approached the competitiveness of producers.

\section{Research overview}

Competitiveness of rice farming households is affected by many different factors. In particular, the characteristics, knowledge and skill level of the head of household are the first basic factors affecting the production decisions and business of the household. Next, resources (land area, labor, and other household assets) directly affect competitiveness. The accessibility to capital resources to production and business of households, seed starting supplies from trusted organizations such as enterprises, Research Institute, Extension agency also have greatly affects to the productivity and quality of products of household production. Market access to consume products is also a factor affecting household competitiveness.

\section{Factor group of agricultural production conditions}

Agricultural production conditions have a great influence on the competitiveness of the rice industry. Because to comply with these standards, in addition to requirements for household production conditions play important role deciding the competitiveness of the sector. Production conditions include natural conditions such as climate, land, soil and socio-economic conditions such as technical infrastructure, cultivated areas, human resources and initial capital. Vu Thi Minh (2004), Nguyen Sinh Cong (2004) and Mwanza (2011), Zhou and Jin (2009), Nguyen Huu Tin and Phan Thi Giac Tam (2008).

\section{Factor group of household characteristics}

Households play a very important role in agricultural production in Vietnam. In order to improve the competitiveness of the rice industry, it is necessary to carefully study the household's characteristics to have reasonable methods to encourage and changing investment thinking of households, persuade them to invest in rice production ensuring quality and safety. Characteristics of households include: age, education level, experience, gender, household 
size,etc. Nguyen Trong Hoai (2010), Bui Quang Binh (2008), Nguyen Quoc Nghi et al (2011), Pham Anh Ngoc (2008), Okurut et al (2002), Dinh Phi Ho (2006), Huynh Thanh Phuong (2011) etc.

\section{Factor group of market signals}

According to Vu Thi Minh (2004), "The market is the most important factor which has a great impacting to all activities of commodity production in general and producing and trading agricultural crops in particular. The market in agricultural production of households consists of two types: the output market and the input market.

\section{Factor group of support of enterprises and traders}

Restrictions of households such as market access is weak, little capital, scientific and technological knowledge is still limited, ability to take risk still low, etc. These limitations are becoming major barriers to the investment process of agricultural production and improve the competitiveness of the rice industry. The support of enterprise, trader may be good complement households which many shortcomings areas. It is necessary symbiosis to improve the efficiency of investment and development in agricultural production in general and the rice industry in particular. Investment of enterprises, traders and household ' investments will become a combination of complementary values for each other, in which enterprises's investment, traders will supplement capital and input materials which responsible for searching output markets and households will be responsible for the main production to producing quality products. According to Jayasinghe-Mudalige and Henson (2007), large enterprises have the capacity to implement food safety controls, whereas most small enterprises do not want to do. Small enterprises have afford and capacity is still not really interested in food safety control competence, wherewithal it is even more and more difficult for households to implement food safety control. This has a great effect to the competitiveness of the rice industry.

\section{Factor group of government support}

According to Nelson (1987), government intervention is largely an empirical issue that is not a theoretical issue because there is no normative theory meets the requirements of the appropriate role of government in a mixed economy and no theories about the diversity of institutional arrangements to resolve common problems.

Can see the role of the government in promoting and enhancing rice sector competitiveness is expressed in two dimensions. 
Management roles: Henson and Caswell, 1999; Ogus, 1994

Supporting role: In addition to the function of issuing and controlling compliance with food safety standards, in developing countries, the state plays an important role in supporting production facilities apply food safety standards including GAP (Hanak et al., 2002; Wannamolee, 2008). State support policies for other actors in the production chain as consumers are also mentioned (Srimanee and Routray, 2012).

\section{Research Methodology}

\subsection{Data collection methods}

Primary data was collected through direct interviews with questionnaires for 350 rice farming households. The results after removing unreliable observations left 329 observations (a good response rate of $94 \%)$, specifically:

Table 1: Statistics Survey Samples

\begin{tabular}{|l|l|c|l|}
\hline Stt & Research areas & Number of observations & Structure \\
\hline 1 & Northern (Red River Delta) & 119 & $36,2 \%$ \\
\hline 2 & South (Mekong Delta) & 121 & $36,8 \%$ \\
\hline 3 & Central (Central Coast) & 89 & $27,0 \%$ \\
\hline Tổng & & 329 & $100 \%$ \\
\hline
\end{tabular}

Source: Survey results from 329 rice farming households in Vietnam

\subsection{Data Analysis Methods}

The study uses exploratory factor analysis (EFA) to perform this analysis. After performing data analysis, the author performed data analysis using the method of comparing and interpreting research findings.

\section{Research findings}

Before analyzing the exploratory factor, the author performs a scale test, the results are as follows:

Table 2: Quality test of scale

\begin{tabular}{|l|l|l|}
\hline \multicolumn{1}{|c|}{ Factors } & \multicolumn{1}{|c|}{ Item } & \multicolumn{1}{c|}{ Cronbach's Alpha } \\
\hline Production conditions & $\begin{array}{l}\text { DKSX1, DKSX2, DKSX3, DKSX4, } \\
\text { DKSX5, DKSX6, DKSX7 }\end{array}$ & 0,944 \\
\hline Household characteristics & DDNH1, DDNH2, DDNH3, DDNH4, & 0,938 \\
\hline
\end{tabular}




\begin{tabular}{|l|l|l|}
\hline & DDNH5 & \\
\hline Market signals & THTT1, THTT2, THTT3 & 0,763 \\
\hline Support of enterprises and traders & DNTL1, DNTL2, DNTL3 & 0,719 \\
\hline Government support & $\begin{array}{l}\text { HTNN1, HTNN2, HTNN3, HTNN4, } \\
\text { HTNN5, }\end{array}$ & 0,863 \\
\hline Competitiveness of rice industry & $\begin{array}{l}\text { NLCT1, NLCT2, NLCT3, NLCT4, } \\
\text { NLCT5, }\end{array}$ & 0,833 \\
\hline
\end{tabular}

\section{Source: Analysis from survey results}

One factor is rated well when the Cronbach's alpha coefficient is greater than or equal to 0.8 , the Cronbach's alpha coefficient of 0.6 or higher is usable (Peterson, 1994). Thus, through the table we see Cronbach's Alpha of the factors are greater than $0.719>0.6$, so the scale quality is good. After that, the author performed the exploratory factor analysis:

Table 3: Exploratory factor analysis

\section{Rotated Component Matrix ${ }^{a}$}

\begin{tabular}{|c|c|c|c|c|c|}
\hline & \multicolumn{5}{|c|}{ Component } \\
\hline & 1 & 2 & 3 & 4 & 5 \\
\hline DKSX5 & 0,918 & & & & \\
\hline DKSX4 & 0,906 & & & & \\
\hline DKSX2 & 0,905 & & & & \\
\hline DKSX3 & 0,903 & & & & \\
\hline DKSX7 & 0,896 & & & & \\
\hline DKSX6 & 0,830 & & & & \\
\hline DKSX1 & 0,636 & & & & \\
\hline DDNH4 & & 0,936 & & & \\
\hline DDNH2 & & 0,914 & & & \\
\hline DDNH5 & & 0,879 & & & \\
\hline DDNH3 & & 0,869 & & & \\
\hline DDNH1 & & 0,869 & & & \\
\hline HTNN4 & & & 0,822 & & \\
\hline HTNN3 & & & 0,811 & & \\
\hline HTNN2 & & & 0,797 & & \\
\hline HTNN1 & & & 0,780 & & \\
\hline
\end{tabular}




\begin{tabular}{|l|l|l|l|l|l|} 
HTNN5 & & & 0,756 & \\
THTT1 & & & & 0,970 & \\
THTT2 & & & & 0,769 & \\
DNTL2 & & & & 0,739 & \\
DNTL1 & & & & & 0,808 \\
DNTL3 & & & & & 0,792 \\
\hline Eigenvalues & 5,774 & 4,346 & 2,769 & 2,036 & 1,840 \\
\hline Cumulative (\%) & 25,103 & 43,997 & 56,036 & 64,887 & 72,888 \\
\hline Kaiser-Meyer-Olkin Measure of Sampling Adequacy. & & & 0,793 \\
\hline Bartlett's Test of Sphericity & Approx. Chi-Square & 5979,124 \\
\hline & Df & & 0,000 \\
\hline
\end{tabular}

Extraction Method: Principal Component Analysis.

Rotation Method: Varimax with Kaiser Normalization.

a. Rotation converged in 5 iterations.

\section{Source: Analysis from survey results}

According to the results in the table above, $\mathrm{KMO}=0,793$ factor analysis is appropriate. Testing the hypothesis H0 Bartlett review: correlation between the observed variables equal zero in the overall. If this test is statistically significant (Sig 5 0.05), the observed variables are correlated with each other overall (Hair el al., 2006). Accordingly, the sig of the above test is $0,000<0.05$, so the variables are correlated with each other in the overall. With the results of KMO coefficient and Bartlett testing in the above table, it shows that there are enough conditions to conduct factor analysis.

Five factors have Eigenvalues (the amount of variation explained by the factor) greater than 1 is extracted from the original 25 items; and Cumulative with a value of $71.1 \%$ tells us that these 5 factors explain $71.1 \%$ of the variability of data (Gerbing and Anderson, 1988).

Thus, based on Rotated Component Matrix from EFA analysis 5 factors have been created from 23 items are: Factor 1 includes 7 items, named DKSX: Production conditions; Factor 2 includes 5 items, named DDNH: Households characteristics; Factor 3 includes 5 items, named HTNN: Government support; Factor 4 includes 3 items, named THTT: Market Signals; Factor 5 includes 3 items, named DNTL: Support of enterprises and traders 


\section{Recommendations}

To enhance the competitiveness of Vietnam's rice industry, from research findings, the authors propose a number of recommendations as follows:

First, the government should open further training courses on techniques of rice for the people care to help people gain access to more modern techniques.

Secondly, for households, they also need to access market requirements for rice products.

Third, households also need to improve more specialized knowledge, techniques to meet the production requirements, thus creating quality products, meeting the requirements of the market.

\section{Acknowledgement}

Author would like to express my special thanks to Thai Nguyen University of Technology for giving me the permission to use all required equipment and the necessary materials to complete the report.

\section{References}

Bui Quang Binh (2008), "Human capital and income of coffee cultivators in Tay Nguyen" Master Thesis in Economics, University of Economics Ho Chi Minh City

Dinh Phi Ho (2006), Development Economics, Statistical Publishing House, Ho Chi Minh City

Henson, S., \& Caswell, J. (1999), “Food safety regulation: an overview of contemporary issues", Food policy, vol. 24, issue 6, pp. 589-603.

Huynh Thanh Phuong (2011), Factors affecting the income of non-agricultural, Master thesis, Ho Chi Minh City Open University

Nelson, R. R. (1987), "Roles of government in a mixed economy", Journal of Policy Analysis and Management, vol. 6, issue 4, pp. 541-550.

Nguyen Huu Tin and Phan Thi Giac Tam (2008), "Research on the impact of access to the infrastructure of the household income in Cho Moi district, An Giang province" Science Journal of An Giang University, No. 34, p. 25-28

Nguyen Quoc Nghi, Tran Que Anh and Bui Van Trinh (2011), "Factors affecting household incomes in rural areas of Tra On district, Vinh Long province", Science Journal, Ho Chi Minh City Open University, Number 5, Episode 23, pp.30-36,

Nguyen Sinh Cong (2004), Factors affecting income and poverty in Co Do district - TP. Can Tho, Master thesis, University of Economics Ho Chi Minh City 
Journal of Business Management and Economic Research (JOBMER), vol.3, issue.5, pp.21-28

Nguyen Trong Hoai (2010), Development Economics, Labour and Social Publising House, Ho Chi Minh City

Ogus, A. I. (1994), Regulation: Legal form and economic theory, Oxford: Clarendon Press.

Okurut et al (2002), Determinants of regional poverty in Uganda, African Economic Research Consortium, Nairobi

$\mathrm{Vu}$ Thi Minh (2004), Developing fruit trees in mountainous areas of Quang Ninh province, National Economics University Publishing House.

Zhou, J. \& Jin, S. (2009), Adoption of Food Safety Quality Standards: A Way out of Monitoring Production Practices of Numerous Small-scale Farmers? the International Association of Agricultural Economists, Beijing, China. 